\title{
Digestibilidade intestinal in vitro da proteína de coprodutos da indústria do biodiesel
}

\author{
[Intestinal protein digestibility of by-products from biodiesel industry] \\ G.S. Couto ${ }^{1}$, J.C. Silva Filho ${ }^{2}$, A.D. Corrêa ${ }^{2}$, E.A. Silva ${ }^{3,6}$, R.M.P. Pardo ${ }^{1,4}$, C. Esteves ${ }^{5}$ \\ ${ }^{1}$ Aluno de pós-graduação - Universidade Federal de Lavras - Lavras, MG \\ ${ }^{2}$ Universidade Federal de Minas Gerais - Lavras, MG \\ ${ }^{3}$ EPAMIG/Uberaba, MG \\ ${ }^{4}$ Faculdade de Ciências Agropecuárias - Universidade de Sucre - Sincelejo, Colombia \\ ${ }^{5}$ Aluna de graduação - Universidade Federal de Lavras - Lavras, MG \\ ${ }^{6}$ Bolsista de produtividade - INCT-CA
}

\begin{abstract}
RESUMO
Determinou-se a digestibilidade intestinal (DI) da proteína de vários coprodutos do biodiesel nas formas de farelo e torta. Foram avaliados oito coprodutos: tortas e farelos de pinhão manso, nabo forrageiro, tremoço, algodão. Os coprodutos foram incubados no rúmen por 16 horas, e os resíduos não degradados no rúmen submetidos à digestão enzimática com solução de pepsina e pancreatina para a determinação da DI. Ainda, nos resíduos da incubação ruminal, foram determinadas: degradabilidade da matéria seca (DR), proteína degradável no rúmen (PDR) e proteína não degradável no rúmen (PNDR). A digestibilidade intestinal da proteína para os coprodutos do biodiesel variou de 2,4 a $48,6 \%$. Todos os coprodutos avaliados caracterizaram-se como alimentos de alto teor proteico, sendo considerados de alta PDR, e apresentaram baixa digestibilidade intestinal da proteína. A DI da proteína dos coprodutos do biodiesel na forma de torta foi maior em comparação com a dos farelos. A torta e o farelo de algodão apresentaram os maiores coeficientes de DI.
\end{abstract}

Palavras-chave: rúmen, oleaginosas, proteína degradável, proteína digestível, proteína não degradável

\begin{abstract}
The objective of this research was to determine intestinal protein digestibility (ID) of some biodiesel byproducts in the form of cakes and the meals. Eight by-products were: cakes and meals of physic nut, turnip, lupine, cotton cake, cottonseed meal. The by-products were incubated in the rumen for 16 hours, were the undegradable rumen residues were submitted to enzymatic digestion with pepsin and pancreatin solution for the determination of ID. In the incubation residues the following was also determined: dry matter degradability $(R D)$, rumen degradable protein $(R D P)$ and rumen undegradable protein $(R U P)$. The intestinal protein digestibility of biodiesel by-products ranged from 2.4 to $48.6 \%$. All the by-products evaluated in this study were characterized as high protein sources and were considered high-RDP. The by-products presented low intestinal protein digestibility. The ID protein of biodiesel by-products was higher in the cakes than the meals. The by-products evaluated, the cottonseed cake and meal presented the highest ID coefficients.
\end{abstract}

Keywords: rumen, oil, degradable protein, digestible protein, undegradable protein

\section{INTRODUÇÃO}

Com o propósito da utilização do biodiesel como fonte de biocombustível, estão sendo disponibilizados vários subprodutos no mercado, oriundos da extração de óleo. A geração desses coprodutos deve ser foco de análises mais detalhadas, pois eles podem ser um fator determinante para a viabilidade econômica da produção desse combustível.

Recebido em 18 de agosto de 2011

Aceito em 3 de abril de 2012

E-mail: gust_couto@hotmail.com

Apoio: FAPEMIG e CNPq 
O estudo da digestibilidade intestinal (DI) da proteína dos coprodutos do biodiesel é de grande importância para as áreas de produção e nutrição animal, pois existe uma grande variabilidade entre os alimentos. A digestibilidade in vitro tem sido utilizada extensivamente nas análises de alimentos, pois apresenta uma alta correlação com a digestibilidade in vivo (Silva e Queiróz, 2002).

Segundo Haugen et al. (2006), o sistema de avaliação proteica para gado de leite (National..., 2001) reconhece que existem diferenças entre alimentos em relação à digestibilidade intestinal das proteínas. Antes da revisão de 2001, a digestibilidade intestinal da proteína não degradável no rúmen (PNDR) era considerada constante para todos os alimentos $(80 \%)$, igual ao sistema de avaliação proteica para gado de corte (National..., 1996), o qual ainda mantém essa constância para os alimentos, portanto este valor constante foi considerado devido à falta de informação em relação aos valores da digestibilidade da PNDR dos alimentos. O NRC (National..., 2001) para gado leiteiro já considera valores entre 50 e $100 \%$. A variabilidade entre alimentos está em função do tipo de alimento, tipo e grau de processamento, entre outros fatores (Calsamiglia e Stern, 1995). Branco et al. (2006) determinaram a DI de vários alimentos para ruminantes usando várias metodologias e concluíram que é o valor da DI que deve ser considerado na hora de formular uma dieta, devido à variabilidade que existe entre eles.

Objetivou-se com esta pesquisa determinar a digestibilidade intestinal da proteína de vários coprodutos do biodiesel nas formas de farelo e torta.

\section{MATERIAL E MÉTODOS}

Foram avaliados os seguintes coprodutos: pinhão manso (Jatropha curcas), nabo forrageiro (Raphanus sativus), tremoço (Lupinus albus L) e algodão (Gossypium hirsutum), nas formas de tortas e farelos. O farelo de algodão usado neste trabalho continha $38 \%$ de proteína bruta $(\mathrm{PB})$ e foi adquirido de uma fonte comercial.

As amostras foram submetidas à extração mecânica a frio, utilizando-se uma prensa mecânica tipo expeller em aço inoxidável, modelo MPE - 40, resultando nas tortas que foram utilizadas no experimento. Para a obtenção dos farelos, realizou-se a extração química do óleo da torta resultante da extração mecânica, utilizando-se um extrator do tipo Soxlet. As amostras das tortas foram deixadas em refluxo com $150 \mathrm{~mL}$ de hexano por aproximadamente três horas. Após o refluxo, as amostras foram secas em estufa a $80^{\circ} \mathrm{C}$ para evaporação total do solvente.

Determinaram-se matéria seca (MS), PB, matéria mineral (MM) e extrato etéreo (EE) conforme os procedimentos descritos pela AOAC (Association..., 1990), além da porcentagem de carboidratos não fibrosos $(\mathrm{CNF})$, estimados pela equação proposta pelo NRC (2001): $\mathrm{CNF}=100$ $-(\% \mathrm{FDN}+\% \mathrm{~PB}+\% \mathrm{EE}+\% \mathrm{MM})$. As determinações de fibra em detergente neutro (FDN) e fibra em detergente ácido (FDA) foram feitas segundo Van Soest (1967). Todas as determinações foram feitas em triplicata.

A avaliação da degradabilidade foi determinada pela incubação in situ das amostras dos diferentes coprodutos, por 16 horas, de acordo com a metodologia descrita por Calsamiglia e Stern (1995), utilizando-se duas vacas com cânula no rúmen. Logo em seguida, as bolsas com as amostras foram lavadas cinco vezes durante dez minutos de cada vez, em máquina lavadora. As amostras foram, então, levadas à estufa a $55^{\circ} \mathrm{C}$ por 48 horas. Considerou-se como PNDR a proteína encontrada nos resíduos de incubação após as 16 horas. A proteína degradada no rúmen (PDR) foi calculada pela diferença da PNDR. Após a incubação ruminal, a digestibilidade intestinal dos diferentes materiais foi determinada mediante a aplicação dos procedimentos in vitro descritos por GonzálezGalan et al. (2008).

Os dados da digestibilidade intestinal da proteína foram analisados mediante um esquema fatorial $4 \times 2$ com oito tratamentos, ou seja, quatro coprodutos com dois tipos de processamento, torta e farelo. Para a realização das análises, foi utilizado o SISVAR (Ferreira, 2000).

\section{RESULTADOS E DISCUSSÃO}

Os resultados da análise bromatológica dos coprodutos são apresentados na Tab. 1. Os valores de matéria seca (MS) encontrados para os dois tipos de processamento não variaram 
demonstrando que as sementes passaram pelo processo de extração de óleo com uma concentração muito baixa de água. Quanto ao teor de PB dos coprodutos avaliados, a maioria apresentou teores acima de $20 \%$, caracterizandose como concentrados proteicos. Em relação ao tipo de processamento, os farelos apresentaram maiores teores de PB que as tortas.

A elevada concentração de EE nas tortas deve-se à ineficiência do processo de extração do óleo. A extração por solventes demonstrou ser mais eficiente, originando os farelos. A utilização de fontes de gordura de origem vegetal, como óleos e sementes oleaginosas, é uma das alternativas empregadas para aumentar a densidade energética na dieta por estar relacionada ao aumento nos teores de nutrientes digestíveis totais (NDT).

Considerando-se que as dietas de ruminantes contêm, em média, cerca de 3\% de lipídios, uma suplementação de gordura deve levar em consideração a quantidade e a fonte de lipídios para que haja efeito mínimo na fermentação ruminal, já que as gorduras insaturadas possuem efeitos inibitórios sobre os microrganismos celulolíticos. Diversos pesquisadores afirmam que teores maiores que $7 \%$ de lipídios na dieta interferem negativamente na fermentação ruminal (Palmquist, 1989; Jenkins, 1995).

Tabela 1. Composição bromatológica das tortas de tremoço (TT), nabo forrageiro (TN), pinhão manso (TP), algodão (TA), farelos de tremoço (FT), nabo forrageiro (FN), pinhão manso (FP), algodão $38 \%$ (FA) em \% de matéria seca (MS) e nutrientes digestíveis totais (NDT)

\begin{tabular}{lllllllll} 
Coproduto & MS $^{*}$ & PB & NDT $^{1}$ & EE & FDN & FDA & CNF $^{2}$ & MM \\
\hline TT & 90,53 & 39,95 & 88,09 & 11,65 & 14,28 & 11,33 & 31,35 & 2,77 \\
TN & 92,20 & 35,49 & 97,18 & 24,32 & 15,29 & 13,35 & 16,62 & 8,29 \\
TP & 92,83 & 19,82 & 66,13 & 26,19 & 40,81 & 38,04 & 8,21 & 4,98 \\
TA & 94,18 & 26,91 & 49,18 & 11,26 & 56,50 & 37,14 & 1,14 & 4,20 \\
FT & 90,95 & 42,91 & 66,73 & 0,74 & 25,14 & 20,06 & 27,78 & 3,44 \\
FN & 91,68 & 53,08 & 66,18 & 1,54 & 31,05 & 20,13 & 0,37 & 13,96 \\
FP & 92,39 & 27,81 & 27,57 & 2,38 & 60,20 & 52,45 & 3,23 & 6,38 \\
FA & 91,60 & 47,73 & 65,27 & 0,91 & 27,63 & 19,15 & 17,22 & 6,51 \\
\hline
\end{tabular}

*Com base na matéria natural.

${ }^{1}$ Calculado de acordo com Kearl (1982)

${ }^{2}$ Calculado de acordo com NRC (2001).

Em relação à degradabilidade ruminal (DR) da MS, a interação foi significativa $(\mathrm{P}<0,05)$, mostrando que o tipo de processamento interfere nela (Tab. 2).

O farelo de nabo forrageiro foi o coproduto que apresentou maior degradabilidade, e a menor $(\mathrm{P}<0,05)$ foi observada para o farelo de pinhão manso. As degradabilidades do farelo de nabo forrageiro e da torta de tremoço foram superiores às dos outros coprodutos, sendo que o teor de DR do farelo de algodão está acima dos observados por Rodriguez et al. (2003) e Aroeira et al. (1993), que foram de 65,0 e $74,7 \%$, respectivamente, admitindo-se que essa variação provavelmente esteja relacionada ao tipo de processamento do material, pois o farelo de algodão tem variação na porcentagem de fibra.

A torta de tremoço foi a que apresentou maior degradabilidade, sendo que os menores teores foram observados para as tortas de pinhão manso e algodão, que não diferiram entre si, ficando próximos dos $45,9 \%$ encontrados por Pinto et al. (2007), para a degradabilidade da cana-deaçúcar. Mello et al. (2008) avaliaram a degradabilidade da torta de nabo forrageiro em diferentes tempos de incubação $(3,6,12,24$, e 72 horas) e encontraram valores de $93,8 \%$; bem acima, portanto, dos encontrados neste experimento, que foram de 72,8\%. Deve-se lembrar que o tempo de incubação foi de 16 horas. Para o pinhão manso, não houve diferença significativa $(\mathrm{P}>0,05)$ para o tipo de processamento com respeito à degradabilidade.

Os coprodutos avaliados apresentaram menores valores de DR, exceto para a torta de tremoço, em que não houve diferença significativa.

A baixa degradabilidade ruminal relacionada ao tempo de 16 horas de incubação, conforme 
metodologia descrita por Calsamigia e Stern (1995), observada para as tortas de nabo forrageiro, pinhão manso e algodão, pode estar relacionada com o alto teor de EE ou com a composição dos ácidos graxos, pois os tipos de lipídios empregados nas dietas podem influenciar a fermentação e a digestibilidade ruminal da fibra, por meio da supressão das bactérias celulolíticas (Palmquist e Jenkins, 1980; Chalupa et al., 1984; Van Soest, 1994). A redução da DR pode ser considerada um mecanismo físico de recobrimento da fibra com gordura, dificultando o ataque microbiano e provocando efeitos tóxicos diretamente sobre certos microrganismos, além de redução na disponibilidade de cátions por se combinarem com os ácidos graxos (Palmquist e Jenkins, 1980; Grummer et al., 1990). Para a torta de tremoço, não houve influência do teor de EE, pois o comportamento foi contrário.
A baixa degradabilidade dos coprodutos avaliados também pode estar relacionada à menor qualidade das fibras, ou seja, dos componentes da parede celular, o que pode estar relacionado com a baixa DR do pinhão manso, considerando-se sua alta porcentagem de FDN observada na Tab. 1. A lignina, pela ligação aos carboidratos da parede celular, previne a expansão e, consequentemente, deprime a digestibilidade da fibra (Tovar-Gomez et al., 1997).

Os coprodutos tremoço e algodão apresentaram diferença $(\mathrm{P}<0,05)$ em relação ao tipo de processamento para a PDR: o farelo de tremoço apresentou maior porcentagem de PDR em comparação com a sua torta, e em relação ao algodão, a torta apresentou maior porcentagem de PDR (Tab. 2).

Tabela 2. Interação torta versus farelos de coprodutos avaliados juntamente com teores de degradabilidade ruminal (DR) da matéria seca (MS) em 16 horas de incubação, proteína degradada no rúmen (PDR), proteína não degradada no rúmen (PNDR) e digestibilidade intestinal (DI) da PNDR

\begin{tabular}{|c|c|c|c|c|c|c|c|c|c|}
\hline \multirow{2}{*}{$\begin{array}{l}\text { Variável } \\
(\%)\end{array}$} & \multirow{2}{*}{ Produto } & \multicolumn{4}{|c|}{ Tratamentos } & \multicolumn{2}{|c|}{ Fator } & \multirow{2}{*}{$\frac{\text { Int. }}{\text { PxC }}$} & \multirow{2}{*}{ EPM } \\
\hline & & Tremoço & Nabo & Pinhão & Algodão & $\mathrm{P}$ & $\mathrm{C}$ & & \\
\hline \multirow{2}{*}{$\begin{array}{l}\text { DR } \\
(\mathrm{MS})\end{array}$} & Farelo & $83,60 \mathrm{Bb}$ & $90,69 \mathrm{Aa}$ & $48,97 \mathrm{Ca}$ & $85,76 \mathrm{Ba}$ & \multirow{2}{*}{$* * *$} & \multirow{2}{*}{$* * *$} & \multirow{2}{*}{$* * *$} & \multirow{2}{*}{1,13} \\
\hline & Torta & $91,84 \mathrm{Aa}$ & $72,83 \mathrm{Bb}$ & $47,83 \mathrm{Ca}$ & $44,51 \mathrm{Cb}$ & & & & \\
\hline \multirow{2}{*}{ PDR } & Farelo & $94,66 \mathrm{Aa}$ & $82,49 \mathrm{Ba}$ & $96,00 \mathrm{Aa}$ & $74,27 \mathrm{Cb}$ & \multirow{2}{*}{$* * *$} & \multirow{2}{*}{$* * *$} & \multirow{2}{*}{$* * *$} & \multirow{2}{*}{0,54} \\
\hline & Torta & $93,41 \mathrm{Bb}$ & $83,31 \mathrm{Ca}$ & $95,92 \mathrm{Aa}$ & $82,12 \mathrm{Ca}$ & & & & \\
\hline \multirow{2}{*}{ PNDR } & Farelo & $5,34 \mathrm{Cb}$ & $17,51 \mathrm{Ba}$ & $4,00 \mathrm{Ca}$ & $25,73 \mathrm{Aa}$ & \multirow{2}{*}{$* * *$} & \multirow{2}{*}{$* * *$} & \multirow{2}{*}{$* * *$} & \multirow{2}{*}{0,54} \\
\hline & Torta & $6,59 \mathrm{Ba}$ & $16,69 \mathrm{Aa}$ & $4,08 \mathrm{Ca}$ & $17,88 \mathrm{Ab}$ & & & & \\
\hline \multirow{2}{*}{ DI } & Farelo & $20,53 \mathrm{Cb}$ & $30,38 \mathrm{Bb}$ & $2,41 \mathrm{Db}$ & $48,02 \mathrm{Aa}$ & \multirow{2}{*}{$* * *$} & \multirow{2}{*}{$* * *$} & \multirow{2}{*}{$* * *$} & \multirow{2}{*}{0,42} \\
\hline & Torta & $39,16 \mathrm{Ba}$ & $38,94 \mathrm{Ba}$ & $10,18 \mathrm{Ca}$ & $48,62 \mathrm{Aa}$ & & & & \\
\hline
\end{tabular}

Médias seguidas de letras distintas diferem entre si pelo teste Tukey.

$(* * *)=\mathrm{P}<0,001$.

Letras maiúsculas comparam os coprodutos na linha dentro de um único tipo de produto.

Letras minúsculas comparam os dois tipos de produto em cada coproduto na coluna.

A DI foi corrigida para caseína a $100 \%$.

$\mathrm{P}=$ produto $; \mathrm{C}=$ coproduto.

$\mathrm{EPM}=$ erro-padrão da média.

A torta de nabo forrageiro apresentou teor de PDR bem abaixo do encontrado por Mello et al. (2008), que foi de 97,4\%. Essa diferença se deve, provavelmente, ao tempo de incubação, uma vez que o presente experimento utilizou-se de apenas um tempo de incubação, o que também pôde ser observado para a degradabilidade.

Entre os farelos, a porcentagem de PDR foi maior para o tremoço e para o pinhão manso, não apresentando diferenças entre eles $(\mathrm{P}>0,05)$. Entre todos os coprodutos avaliados, o farelo de algodão foi o que apresentou o menor valor para PDR (74,3\%), diferindo dos demais coprodutos $(\mathrm{P}<0,05)$. A baixa porcentagem de PDR para o farelo de algodão se deve ao tipo de processamento do material, pois trata-se de uma fonte comercial em que a composição química é variável dependendo da variedade plantada e da quantidade de cascas extraídas durante o processo, sendo que este valor foi bem próximo do encontrado por Rodriguez et al. (2003), em cujo trabalho a PDR foi de 75,9\%. Cabral et al. (2001) encontraram valor diferente, $64,7 \%$ de 
PDR, sendo esta diferença relacionada ao tipo de farelo utilizado, pois existe grande variação na quantidade de fibras encontradas, o que vai interferir no teor de PB final. Aroeira et al. (1993) e Cunha et al. (1998), ao utilizarem um maior tempo de incubação ruminal, reportaram valores de 89,7 e $93,5 \%$, respectivamente.

As tortas e os farelos dos coprodutos avaliados caracterizam-se por serem alimentos com alta porcentagem de PDR, sendo que o farelo e a torta de pinhão manso e o farelo de tremoço apresentaram maiores teores de PDR. A elevada degradação da PDR observada nestes coprodutos merece atenção especial, quando estes forem utilizados em proporções significativas na dieta, uma vez que podem conduzir a grandes perdas de nitrogênio no rúmen, tornando necessária a inclusão de fontes energéticas de rápida degradação ruminal.

Os coprodutos do tremoço, nabo forrageiro, pinhão manso e algodão tiveram elevada e rápida degradação ruminal da $\mathrm{PB}$, demonstrando serem ingredientes capazes de atender prontamente a demanda microbiana, como fonte de energia e proteína, podendo ser utilizados para maximizar o desenvolvimento microbiano. Os coprodutos tremoço e algodão apresentaram diferença significativa em relação ao tipo de processamento para a PNDR: a torta de tremoço apresentou maior porcentagem de PNDR, em comparação com o seu farelo, e em relação ao algodão, o farelo apresentou maior porcentagem de PNDR (Tab. 2). A PNDR encontrada no farelo de algodão mostrou estar bem próxima do verificado por Rodriguez et al. (2003), em cujo trabalho a PNDR foi de 24,1\%. Cabral et al. (2001) encontraram valor diferente para este coproduto $(35,3 \%$ de PNDR), sendo essa diferença relacionada com o tipo de processamento ou beneficiamento do co-produto. Para o nabo forrageiro e o pinhão manso, não houve interferência do tipo de processamento $(\mathrm{P}>0,05)$.

Entre todos os coprodutos avaliados, a torta de pinhão manso e os farelos de tremoço e pinhão manso foram os que apresentaram os menores valores para PNDR. Isso se deve à alta porcentagem de PDR dos coprodutos, sendo que os farelos de tremoço e pinhão manso não apresentaram diferença significativa entre si.
Para as tortas, a de nabo forrageiro e de algodão apresentaram maior porcentagem de PNDR, diferindo $(\mathrm{P}<0,05)$ das demais, sendo que a menor porcentagem foi observada para a de pinhão manso. Conforme mostra a Tab. 2, as maiores porcentagens de PNDR verificadas para a torta de nabo forrageiro e de algodão resultaram em maior disponibilidade da proteína nos intestinos.

Com respeito à DI da proteína, houve diferenças significativas entre farelos e tortas, e foi observada interação dos tipos de processamento, excetuando o farelo de algodão. As tortas apresentaram os maiores valores de DI em relação aos farelos, com exceção do farelo de algodão. A torta e o farelo de algodão foram os coprodutos que obtiveram os maiores valores para a DI da proteína, em comparação com os coprodutos do biodiesel, mesmo assim foram mais baixos que os $53,7 \%$ relatados por Cabral et al. (2001), para o farelo de algodão, fato que pode estar relacionado à elevada degradação ruminal dessa fonte. Entre as tortas, a de tremoço e nabo forrageiro não diferiram entre si.

As menores porcentagens de DI foram verificadas para o pinhão manso, tanto na forma de farelo como de torta. Branco et al. (2006), ao trabalharem com sementes de girassol, obtiveram valores de PNDR de 4,9\%, próximos ao do pinhão manso, e valores consideravelmente altos para DI $(54,7 \%)$. Portanto, a baixa DI pode não estar relacionada com a quantidade de proteína que escapa da degradação ruminal, e sim com a qualidade dessa proteína presente no intestino delgado, sendo que a presença de fatores antinutricionais pode também contribuir com a baixa DI.

A baixa DI observada para os coprodutos do biodiesel contribui para menor disponibilidade de aminoácidos para absorção no intestino delgado. Este fato pode ser atribuído à elevada degradação ruminal destes alimentos, sugerindo que a proteína que escapa à degradação ruminal esteja associada à porção fibrosa, o que explica a baixa digestão no intestino delgado, como observado na Fig. 1. Para os coprodutos do pinhão manso, existe outro fato que pode estar relacionado com a baixa DI, que é a presença de um fator antinutricional altamente tóxico, o forbol (Makkar et al., 1998; Makkar e Becker, 1999). 
Vários trabalhos vêm contribuindo para demonstrar que a atividade tóxica das sementes e do óleo do pinhão manso se deve à presença de ésteres de forbol e não à curcina, como se pensava anteriormente. Os ésteres de forbol são uma complexa mistura de ésteres do forbol tetracíclico diterpeno, que apresentam atividades carcinogênicas e ação inflamatória (Makkar et al., 1998; Makkar e Becker, 1999).

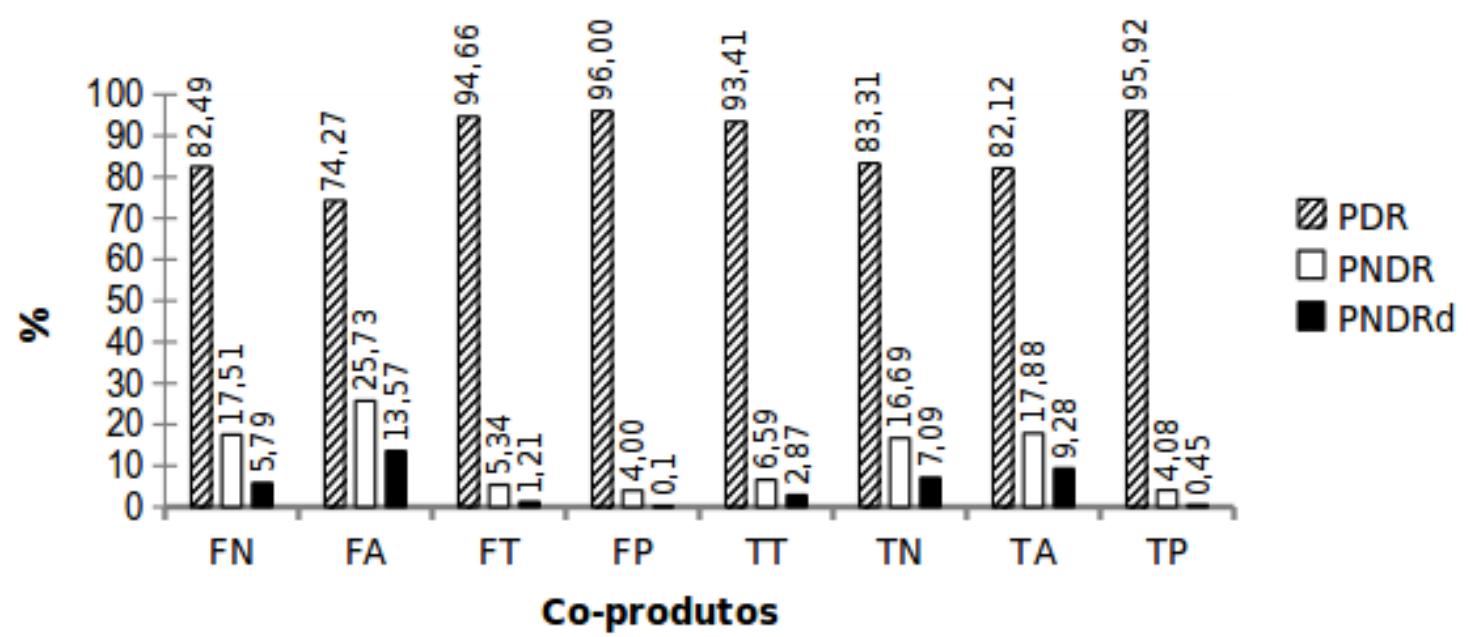

Figura 1 - Proporções relativas da proteína degradada no rúmen (PDR), proteína não degradada no rúmen (PNDR) e proteína não degradada no rúmen digestível no intestino delgado $\left(\mathrm{PNDR}_{\mathrm{d}}\right)$, do farelo de nabo forrageiro (FN), farelo de algodão (FA), farelo de tremoço (FT), farelo de pinhão manso (FP), torta de nabo forrageiro (TN), torta de tremoço (TT), torta de algodão (TA) e da torta de pinhão manso (TP) em relação a proteína bruta total dos coprodutos.

\section{CONCLUSÕES}

Todos os coprodutos avaliados se caracterizaram por serem alimentos de alto teor proteico, sendo considerados de alta PDR. Os coprodutos apresentaram baixa digestibilidade intestinal da proteína. A digestibilidade intestinal da proteína dos co-produtos do biodiesel nas formas de torta e farelo é maior para as tortas em comparação aos farelos. Dos coprodutos avaliados, a torta e o farelo de algodão apresentam os maiores coeficientes de digestibilidade intestinal.

\section{REFERÊNCIAS}

AROEIRA, L.J.M.; SILVEIRA, M.I.; LIZIEIRE, R.S. et al. Degradabilidade no rúmen e taxa de passagem da cana-de-açúcar mais ureia, do farelo de algodão e do farelo de arroz em novilhos mestiços europeu $\mathrm{x}$ zebu. Rev. Bras. Zootec., v.22, p.552-564, 1993.

ASSOCIATION of official agricultural chemists AOAC. Official methods of the Association of Official Agricultural Chemists. 11.ed. Washington, DC, 1990. $1015 \mathrm{p}$.
BRANCO, A.F.; CONEGLIAN, S.M.; MAIA, F.J. et $a l$. Digestibilidade intestinal verdadeira da proteína de alimentos para ruminantes. Rev. Bras. Zootec., v.35, p.788-1795, 2006.

CABRAL, C.S.; VALADARES FILHO, S.C.; MALAFAIA, P.A. Estimação da digestibilidade intestinal da proteína de alimentos por intermédio da técnica de três estádios. Rev. Bras. Zootec., v.30, p.546-552, 2001.

CALSAMIGLIA, S.; STERN, M.D. A three-step in vitro procedure for estimating intestinal digestion of protein in ruminants. J. Anim. Sci., v.73, p.1459-1465, 1995.

CHALUPA, W.; RICKABAUGH, B.; KRONFELD, D.S.; SKLAN, D. Rumen fermentation in vitro as influenced by long chain fatty acids. J. Dairy Sci., v.67, p.1439-1444, 1984.

CUNHA, J.A.; MELOTTI, L.; LUCCI, C.S. Degradabilidade no rúmen da matéria seca e da proteína do caroço integral e do farelo de algodão (Gossypium hirsutum) pela técnica dos sacos de náilon in situ com bovinos. Braz. J. Vet. Res. Anim. Sci., v.35, p.96-100, 1998. 
FERREIRA, D.F. Análises estatísticas por meio do Sisvar para o windows versão 4.0. In: REUNIÃO ANUAL DA REGIÃO BRASILEIRA DA SOCIEDADE INTERNACIONAL DE BIOMETRIAL, 45., 2000, São Carlos. Anais... São Carlos: SIB, 2000. p.255-258.

GONZÁLEZ-GALAN, A.; CORRÊA, A.D.; ABREU, C.M.P. et al. Caracterización quimica de la casina del fruto de Prosopis spp. procedente de Bolivia y Brasil. Arch. Latinoam. Nutr., v.58, p.309-315, 2008.

GRUMMER, R.R.; HATFIELD, M.L.; DENTINE, M.R. Acceptability of fat supplements in four dairy herds. J. Dairy Sci., v.73, p.852-857, 1990.

HAUGEN, H.L.; IVAN, S.K.; MacDONALD, J.C. et al. Determination of undegradable intake protein digestibility of forages using the mobile nylon bag technique. J. Anim. Sci., v.84, p.886-893, 2006.

JENKINS, T.C. Lipid metabolism in the rumen. $J$. Dairy Sci., v.76, p.3851-3863, 1995.

KEARL, L. Nutrients requirements of ruminant in development countries. Logan: Utah State University, 1982. 381p.

MAKKAR, H.P.S.; ADERIBIGBE, A.O.; BECKER, $\mathrm{K}$. Comparative evaluation of non-toxic and toxic varieties of Jatropha curcas for chemical composition, digestibility, protein degradability and toxic factors. Food Chem., v.62, p.207-218, 1998.

MAKKAR, H.P.S.; BECKER, K. Plant toxins and detoxification methods to improve feed quality of tropical seeds. J. Anim. Sci., v.12, p.467-480, 1999.

MELLO, D.F.; FRANZOLIN, R.; FERNANDES, L.B. et al. Avaliação do resíduo de nabo forrageiro extraído da produção de biodiesel como suplemento para bovinos de corte em pastagens. Rev. Bras. Saúde Prod. Anim., v.9, p.45-56, 2008.
NUTRIENTS requirements of beef cattle. 7.ed. Washington: National Academic of Sciences. 1996. 242p.

NUTRIENTS requirements of dairy cattle. 7.ed. Washington: National Academic of Sciences, 2001. 381p.

PALMQUIST, D.L.; JENKINS, T.C. Fat in lactation rations: review. J. Dairy Sci., v.63, p.1-14, 1980.

PALMQUIST, D.L. Suplementação de lipídios para vacas em lactação. In: SIMPÓSIO SOBRE NUTRIÇÃO DE RUMINANTES, 6., 1989, Piracicaba, SP. Anais... Piracicaba: FEALQ, 1989. p.11-25.

PINTO, A.P.; MIZUBUTI, I.Y.; RIBEIRO, E.L.A. et al. Degradabilidade ruminal da cana-de-açúcar integral tratada com diferentes níveis de hidróxido de sódio. Semina Cienc. Agr., v.28, p.503-512, 2007.

RODRIGUEZ, N.M.; MOREIRA, J.F.C.; FERNANDES, P.C.C. et al. Concentrados proteicos para bovinos. 2. Digestão pós-ruminal da matéria seca e da proteína. Arq. Bras. Med. Vet. Zootec., v.55, p.324-333, 2003.

SILVA, D.J.; QUEIROZ, A.C. Análises de alimentos: métodos químicos e biológicos. 3.ed. Viçosa, MG: Editora UFV, 2002. 235p.

TOVAR-GÓMEZ, M.R.; EMILE, J.C.; MICHALETDOREAU, B. et al. In situ degradation kinetics of maize hybrid stalks. Anim. Feed Sci. Tech., v.68, p.7788, 1997.

VAN SOEST, P.J. Development of a comprehensive system of feed analyses and its application to forages. J. Anim. Sci., v.26, p.119-128, 1967.

VAN SOEST, P.J. Nutritional ecology of the ruminant. 2nd. ed. Ithaca, New York (USA): Cornell University Press, 1994. 476p. 